\title{
Formulation of the endophytic fungus Cladosporium oxysporum Berk. \& M.A. Curtis, isolated from Euphorbia bupleuroides subsp. Iuteola, as a new biocontrol tool against the black bean aphid (Aphis fabae Scop.)
}

\author{
Oussama Ali Bensaci ${ }^{1 *}$, Harzallah Daoud ${ }^{2}$, Nadia Lombarkia', Khamsa Rouabah ${ }^{1}$ \\ ${ }^{1}$ Laboratory of Improvement of the Phytosanitary Protection Techniques in Mountainous Agrosystems, Agronomy Department, \\ ISVSA, University Hadj Lakhdar, Batna 05000, Algeria \\ ${ }^{2}$ Laboratory of Applied Microbiology, Faculty of Natural Sciences and Life, University Ferhat Abbas Sétif 1, 19000, Algeria
}

Received: July 16, 2014

Accepted: February 16, 2015

\begin{abstract}
Two formulations containing culture filtrates and conidial suspensions of the endophytic fungus Cladosporium oxysporum Berk. \& M.A. Curtis, isolated previously from stems of Euphorbia bupleuroides subsp. luteola (Kralik) Maire, were experimentally tested for their aphicid activity against the black bean aphid Aphis fabae Scop. found in Algeria. It was shown that invert emulsions are more effective against aphids, than using aqueous suspensions. This was especially true for formulations containing culture filtrates. The relatively insignificant mortalities obtained by formulations containing conidial suspensions indicated a low infectious potential towards the aphids. The proteolytic activity seemed to be more important than the chitinolytic activity of the fungus against the black bean aphid $A$. fabae.
\end{abstract}

Key words: Aphis fabae, bioformulation, Cladosporium oxysporum, endophytes, invert emulsion

\section{Introduction}

Faba bean (Vicia faba L.) is the most cultivated legume in North Africa. Algeria ranks 17th place in the world and 6th across the African continent, preceded by Ethiopia (516,000 tons), Egypt (350,000 tons), Sudan (112,000 tons), Morocco (73,000 tons), and Tunisia (45,000 tons) (Giove and Abis 2007). This crop alone occupies 58,000 ha or $43 \%$ of the area cropped with legumes in Algeria (Maatougui 1996). During the last few years, an outbreak of the black bean aphid (Aphis fabae Scop.) has been recorded in areas planted with the faba bean, in the southern regions of Algeria (Meradsi 2009). This aphid colonises a broad range of Fabaceae species (Bond and Lowe 1975; Cammell 1981; Cammell et al. 1989). Damage caused by the black bean aphid is of a notably indirect nature; by the transmission of viral diseases, such as the Broad bean wilt fabavirus (BBWV) and the Faba bean necrotic yellows nanovirus (FBNYV) (Franz et al. 1996, 1999; Vetten 2010).

Even if chemical treatments are applied; this solution is not satisfactory because insecticides application methods supply little control. This could be particularly seen in active substances which were not altered, thus leading to important outbreaks of aphid colonies. The recently observed insecticide resistance phenomenon, is the result.

Studies on "aphid-pathogenic" fungi and their use as a component of the biological control strategies against this aphid, are not new (Dedryver 1979; Wilding et al. 1986; Yeo et al. 2003; Shah et al. 2004; Assaf 2009; GuesmiJouini et al. 2010; Halimona and Jankevica 2011).
However, it should be noted that many mycotaxa may not produce the desired results because of some technical and bioecological disadvantages, including: slower action (sometimes mandatory pathogenic cycles in the host-insect), instability with respect to some physical factors (moisture, extreme temperatures, and radiations), and obstacles to using these organisms on a large scale. This is why the presentation of the biological control product in its final state, ready for use, must take into account certain essential components such as fast effectiveness and stability. Therefore, endophytic fungi may possibly satisfy the requirements aimed for by plant protectionists.

The main objective of this study was to experimentally evaluate the aphicid activities of two bioformulations prepared from Cladosporium oxysporum Berk. \& M.A. Curtis. Euphorbia bupleuroides subsp. luteola (Kralik) Maire is a spontaneous Euphorbiaceae found in the Aurès region of Algeria. Previously, an endophytic fungus was isolated from E. bupleuroides subsp. luteola, against the black bean aphid. We hypothesised, that this fungus can be exploited in biocontrol programs against several aphids in semi-arid and arid agroecosystems.

\section{Materials and Methods}

Cladosporium oxysporum was previously isolated from healthy stems of E. bupleuroides subsp. luteola, sampled from the Chelia Mountain in the Aurès massif (eastern 
Algeria). Peripheral fragments of fungal colonies from Petri dishes containing potato dextrose agar medium (PDA) amended with tetracyclin and incubated in the dark at $24^{\circ} \mathrm{C}$, were added to the Wickerham liquid medium (Hassan 2007). A relatively large fungal biomass was obtained for subsequent tests. Cultures, contained in the $500 \mathrm{ml}$ Erlenmeyer flasks, were incubated at $24^{\circ} \mathrm{C}$ in darkness. The flasks containing the cultures were subjected to intermittent agitations with magnetic stirrers for 1 to $4 \mathrm{~h}$, for two consecutive weeks.

After three days, we added glucose, at a rate of $1 \mathrm{~g}$ for each Erlenmeyer flask, to energize the growth and biomass gain of the fungus (Sabuquillo et al. 2010). The consequent fungal suspensions were recovered after serial passage in the centrifuge, followed by filtration of the supernatant through sterile Whatman paper 01 and 02 . The filtrates thus obtained were stored at a low temperature $\left(2^{\circ} \mathrm{C}\right)$ under sterile conditions for later use.

Experimental populations of targeted $A$. fabae were obtained in colonies starting from parthenogenetic-viviparous females. Aphids were reared on bean plants of unknown genotypes, planted at the campus of the University of Hadj Lakhdar, Batna, Algeria.

Two prepared bioformulations were tested on the insects' third instars. One bioformulation, an aqueous suspension consisting of the fungal culture filtrates, was incorporated in a $0.75 \% \mathrm{NaCl}$ solution and Tween 80 $(0.02 \%)$. Culture filtrates were used at four concentrations $(20,40,60$, and $80 \%)$. A so-called "invert emulsion" was also prepared. This bioformulation essentially comprises two phases embedded as 1/1: one is aqueous (including fungal fraction) whereas the other is oily, so that a water-in-oil structure is obtained. The aqueous phase contained glycerol $(0.02 \%)$, and salicylic acid $(0.5 \mathrm{~g} / 500 \mathrm{ml}$ of water $)$ in addition to the fungal filtrate. The oily phase consists of two blended vegetable oils of low viscosity, to which Tween 80 was added as an emulsifying agent and a Bohemit clay suspension was also added. The two phases were homogenised with a magnetic stirrer for a few minutes. The same biofomulations were prepared again, but we then added a conidial suspension of different concentrations $\left(10^{5}, 10^{6}, 10^{7}\right.$, and $10^{8}$ conidia $\left.\cdot \mathrm{ml}^{-1}\right)$.

A modified ventilated chamber bioassay (Mesquita et al. 1996) was adopted for the experimental treatments: 20 of the third-instar-apterous aphids were kept in one Petri dish (10 repetitions) containing excised faba bean leaflets. To delay senescence of the leaflets, they were cov- ered on the level of their excision points. For this purpose, sterile cotton containing a mineral solution was used (Mesquita et al. 1996; Butt and Goettel 2000).

The lids of the Petri dishes were perforated and covered with muslin. Aphids were spray-treated using a hand-operated spray bottle (Dorschner et al. 1991). For each bioformulation test, dishes containing untreated A. fabae individuals represented the control units (with the same number of repetitions). Dead insects were recorded at regular intervals (Table 1). The corrected mortality was calculated according to the formula of Abbott (1925).

In the second part of the experiment, and to show a possible relationship between aphicid enzymatic activities of the fungus, two enzymes were quantified: proteases detected using as a substrate, $0.5 \%$ gelatine (Lopez-Llorca et al. 2002), were included in a medium containing $1 \% \operatorname{agar}(\mathrm{w} / \mathrm{v}) \mathrm{NaCl}\left(0.3 \mathrm{~g} \cdot \mathrm{l}^{-1}\right), \mathrm{K}_{2} \mathrm{HPO}_{4}\left(0.2 \mathrm{~g} \cdot \mathrm{l}^{-1}\right)$, and $\mathrm{MgSO}_{4} \cdot 7 \mathrm{H}_{2} \mathrm{O}\left(0.3 \mathrm{~g} \cdot \mathrm{l}^{-1}\right)$. The extent of protease induction was determined according to Moscoso and Rosato (1987) as a ratio of the halo diameter (clear zone indicating the degradation of the substrate) and the colony diameter of the fungus.

For chitinases, fragments of the fungus colonies were added to Erlenmeyer flasks containing $150 \mathrm{ml}$ of a medium. For each 1,000 $\mathrm{ml}$, the medium consisted of colloidal chitin (4 g), $\mathrm{K}_{2} \mathrm{HPO}_{4}(0.7 \mathrm{~g}), \mathrm{MgSO}_{4} \cdot 5 \mathrm{H}_{2} \mathrm{O}(0.5 \mathrm{~g}), \mathrm{KH}_{2} \mathrm{PO}_{4}$ $(0.3 \mathrm{~g}), \mathrm{FeSO}_{4} \cdot 7 \mathrm{H}_{2} \mathrm{O}(0.01 \mathrm{~g})$, peptone (0.5 g), $\mathrm{MnCl}_{2}$ (1.0 $\mathrm{mg})$, and $\mathrm{ZnSO}_{4}(1.0 \mathrm{mg})$. The medium was incubated in darkness at $25^{\circ} \mathrm{C}$ by undergoing regulated intermittent agitations for $30 \mathrm{~min}$ (150 rpm) every $2 \mathrm{~h}$, for 10 days. The culture was cold-centrifuged $\left(4^{\circ} \mathrm{C}\right)$ at $6,000 \mathrm{rpm}$ for 30 min (Nguyen et al. 2009) and filtered through Whatman paper 2. To determine fungal chitinases, every day during the incubation period, we took a volume of $0.9 \mathrm{ml}$ colloidal chitin mixed with sodium acetate $(50 \mathrm{mM})$ and added it to $0.1 \mathrm{ml}$ of the supernatant obtained from the fungal culture. The mixture was then incubated at $37^{\circ} \mathrm{C}$ for $1 \mathrm{~h}$, after which an addition of $0.2 \mathrm{ml}$ of $\mathrm{NaOH}(1 \mathrm{~N})$ was made. This mixture was centrifuged at $8000 \mathrm{rpm}$ for $8 \mathrm{~min}$. The supernatant was recovered for the determination of the reaction product ( $\mathrm{N}$-acetyl- $\beta$-D-glucosamine) by spectrophotometry using a wavelength of $535 \mathrm{~nm}$ every $24 \mathrm{~h}$. This action was done to determine the extent of chitinolytic activity illustrated by enzymatic units. In this way, the quantity of an enzyme able to produce $1 \mu \mathrm{mol}$ of the reduced product per hour was determined (Kuk et al. 2005).

Table 1. Aphicid action and lethal time 50 of bioformulations containing culture filtrates of Cladosporium oxysporum, against Aphis fabae, $48 \mathrm{~h}$ after treatments

\begin{tabular}{|c|c|c|c|}
\hline Formulation & $\begin{array}{c}\text { Concentration of culture filtrates } \\
{[\%]}\end{array}$ & $\begin{array}{l}\text { Corrected mortality } \\
{[\%]}\end{array}$ & $\begin{array}{l}\mathrm{LT}_{50} \\
{[\mathrm{~h}]}\end{array}$ \\
\hline \multirow{4}{*}{ Aqueous suspension } & 20 & 20.94 & 93.94 \\
\hline & 40 & 44.94 & 64.34 \\
\hline & 60 & 46.95 & 66.33 \\
\hline & 80 & 50.44 & 62.17 \\
\hline \multirow{4}{*}{ Invert emulsion } & 20 & 58.44 & 57.08 \\
\hline & 40 & 61.45 & 51.99 \\
\hline & 60 & 82.44 & 43.74 \\
\hline & 80 & 91.94 & 36.11 \\
\hline
\end{tabular}



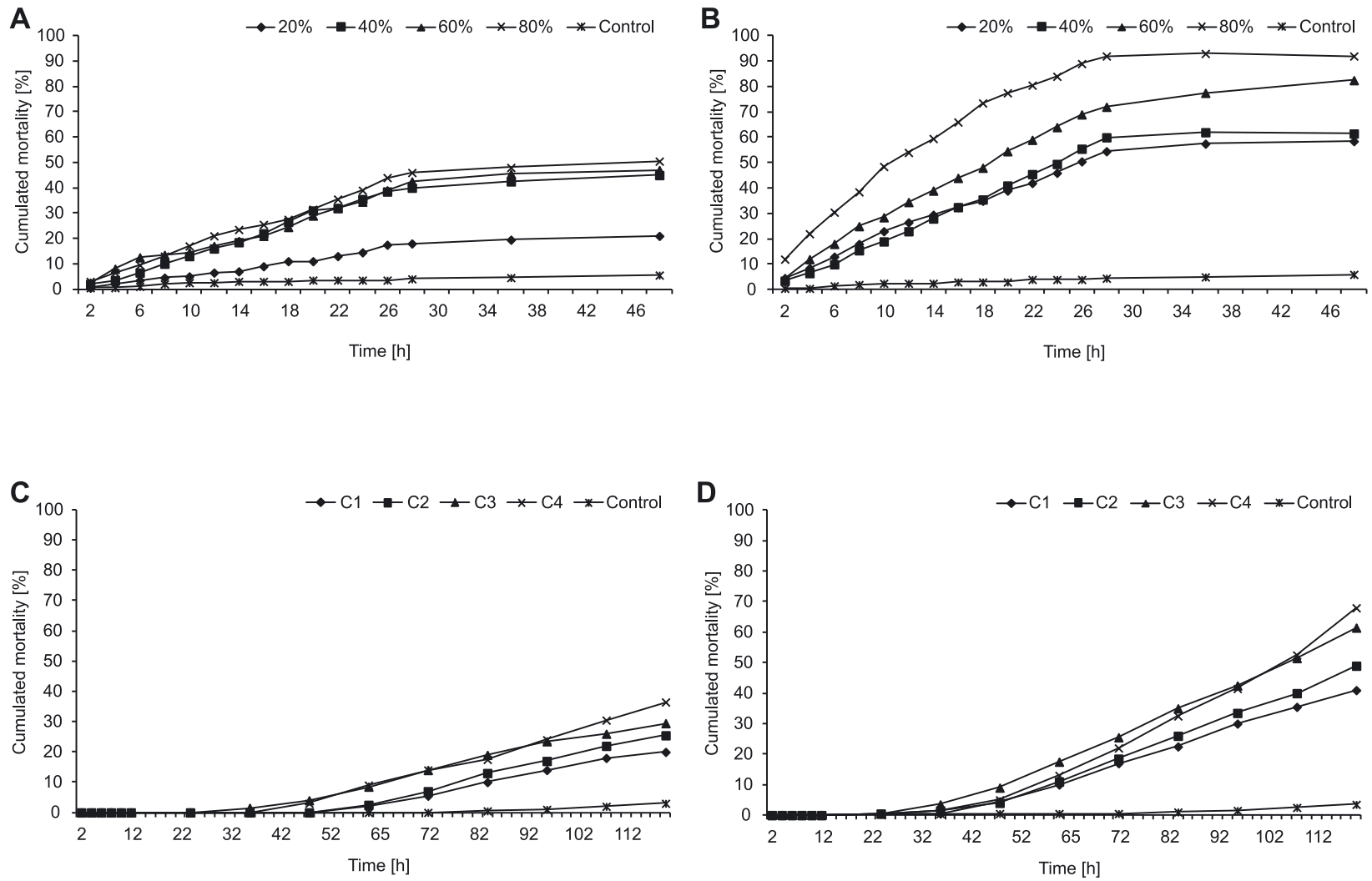

Fig. 1. Cumulated mortality of Aphis fabae individuals after their treatments by the prepared bioformulations containing endophytic Cladosporium oxysporum culture filtrate incorporated in the aqueous suspension (A) and invert emulsion (B) or conidial suspension incorporated in aqueous suspension (C) and invert emulsion (D). C1, C2, C3 and C4 represent the conidial concentration of $10^{5}, 10^{6}, 10^{7}$ and $10^{8}$ conidia $\cdot \mathrm{ml}^{-1}$, respectively

Analysis of variance (ANOVA) was performed to determine the possible effect of the concentrations of the biological matrix (culture filtrates and conidia) on the aphicid activity of the prepared bioformulations. Lethal concentrations $50\left(\mathrm{LC}_{50}\right)$ and lethal times $50\left(\mathrm{LT}_{50}\right)$ were calculated. Following the application of the pesticide, $\mathrm{LT}_{50}$ was estimated. The lethal time, $\mathrm{LT}_{50}$, is the estimate of the time (in hours) it takes the experimental population of the target organism to reach a $50 \%$ mortality. It enabled us to characterise the aphicid-effect precocity of the bioformulation. Probit-logit analysis performed by XLSTAT Pro (Microsoft Office) determined the $\mathrm{LC}_{50}$ and $\mathrm{LT}_{50}$. The probit regression models are illustrated in figures $2 \mathrm{~A}-\mathrm{D}$.

\section{Results}

We recorded different mortalities $48 \mathrm{~h}$ after the application of the bioformulations used against $A$. fabae. These mortalities varied according to the type of bioformulation or according to the concentration of the fungal fraction for the same bioformulation (Table 1). We noted, that aphids treated by invert emulsions record the most important mortalities, from $58.44 \%$ for the lower filtrate concentration to $91.94 \%$ for the highest one (Fig. 1B). Aphids treated with the aqueous suspensions generated mortalities which were much less important. This is mainly illustrated by a mortality of only $50.44 \%$ for the highest concentration of culture filtrate (Fig. 1A).
To determine the aphicid activity of bioformulations containing conidial suspensions of $C$. oxysporum against A. fabae, monitoring had to be done over a prolonged period of post-treatment. The monitoring had to be done because it is normally expected that effects causing fungal infections can occur after hours or days. However, we recorded particularly low mortality rates for aphids treated with the aqueous suspensions compared to aphids treated with the invert emulsions (Table 2). In fact, mortality ranged from $19.97 \%$ for the aqueous suspension with a concentration of $10^{5}$ conidia $\cdot \mathrm{ml}^{-1}$ to only $36.47 \%$ with a concentration of $10^{8}$ conidia $\cdot \mathrm{ml}^{-1}$ (Fig. 1C). Invert emulsions gave more important aphicid action, with $40.96 \%$ of individuals treated by a bioformulation containing $10^{5}$ conidia $\cdot \mathrm{ml}^{-1}$, and $67.96 \%$ for individuals treated by a bioformulation with $10^{8}$ conidia $\cdot \mathrm{ml}^{-1}$ (Fig. 1D).

For the invert emulsions, the $\mathrm{LC}_{50}$ was less, in spite of the biological substrate (Table 3). This was true even if they were correlated negatively (for the same bioformulation) to culture filtrate or the conidia concentrations. In addition, $\mathrm{LT}_{50}$ was relatively shorter after invert emulsion applications, compared to the aqueous suspensions (Table 2). As an example, it was $93.94 \mathrm{~h}$ for the lowest concentration in the culture filtrate $(20 \%)$ in the case of the aqueous suspension, and $57.08 \mathrm{~h}$ for the same substrate concentration in the invert emulsion. The latter recorded the shortest $\mathrm{LT}_{50}$ of $36.11 \mathrm{~h}$ for the highest concentration of the culture filtrate. Furthermore, we opted for the same observations 
Table 2. Aphicid action and lethal time 50 of bioformulations containing conidial suspensions of Cladosporium oxysporum, against Aphis fabae, $120 \mathrm{~h}$ after treatments

\begin{tabular}{|c|c|c|c|}
\hline Formulation & $\begin{array}{c}\text { Conidial concentration } \\
\qquad\left[\mathrm{mll}^{-1}\right]\end{array}$ & $\begin{array}{c}\text { Corrected mortality } \\
{[\%]}\end{array}$ & $\begin{array}{l}\mathrm{LT}_{50} \\
{[\mathrm{~h}]}\end{array}$ \\
\hline \multirow{4}{*}{ Aqueous suspension } & $1 \times 10^{5}$ & 19.97 & 186.35 \\
\hline & $1 \times 10^{6}$ & 25.47 & 175.64 \\
\hline & $1 \times 10^{7}$ & 29.47 & 180.92 \\
\hline & $1 \times 10^{8}$ & 36.47 & 167.04 \\
\hline \multirow{4}{*}{ Invert emulsion } & $1 \times 10^{5}$ & 40.96 & 161.12 \\
\hline & $1 \times 10^{6}$ & 48.97 & 152.94 \\
\hline & $1 \times 10^{7}$ & 61.46 & 141.96 \\
\hline & $1 \times 10^{8}$ & 67.96 & 137.20 \\
\hline
\end{tabular}

Table 3. Lethal concentrations $50\left(\mathrm{LC}_{50}\right)$ of the designed bioformulations regarding Aphis fabae individuals

\begin{tabular}{|c|c|c|c|}
\hline \multicolumn{2}{|c|}{ Culture filtrates } & \multicolumn{2}{|c|}{ Conidia suspensions } \\
\hline aqueous suspension & invert emulsion & aqueous suspension & invert emulsion \\
\hline $58.38 \%$ & $16.06 \%$ & $4.17 \times 10^{9}$ conidia $\cdot \mathrm{ml}^{-1}$ & $4.00 \times 10^{5}$ conidia $\cdot \mathrm{ml}^{-1}$ \\
\hline
\end{tabular}

A
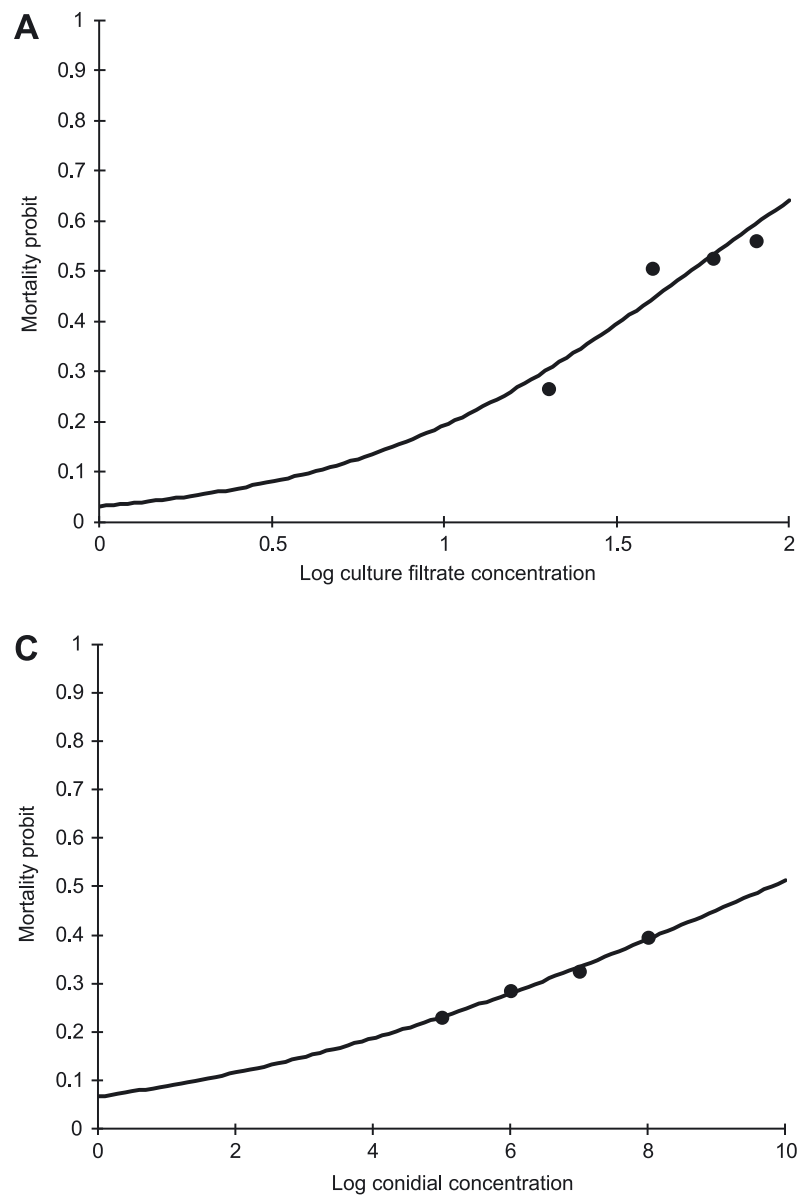
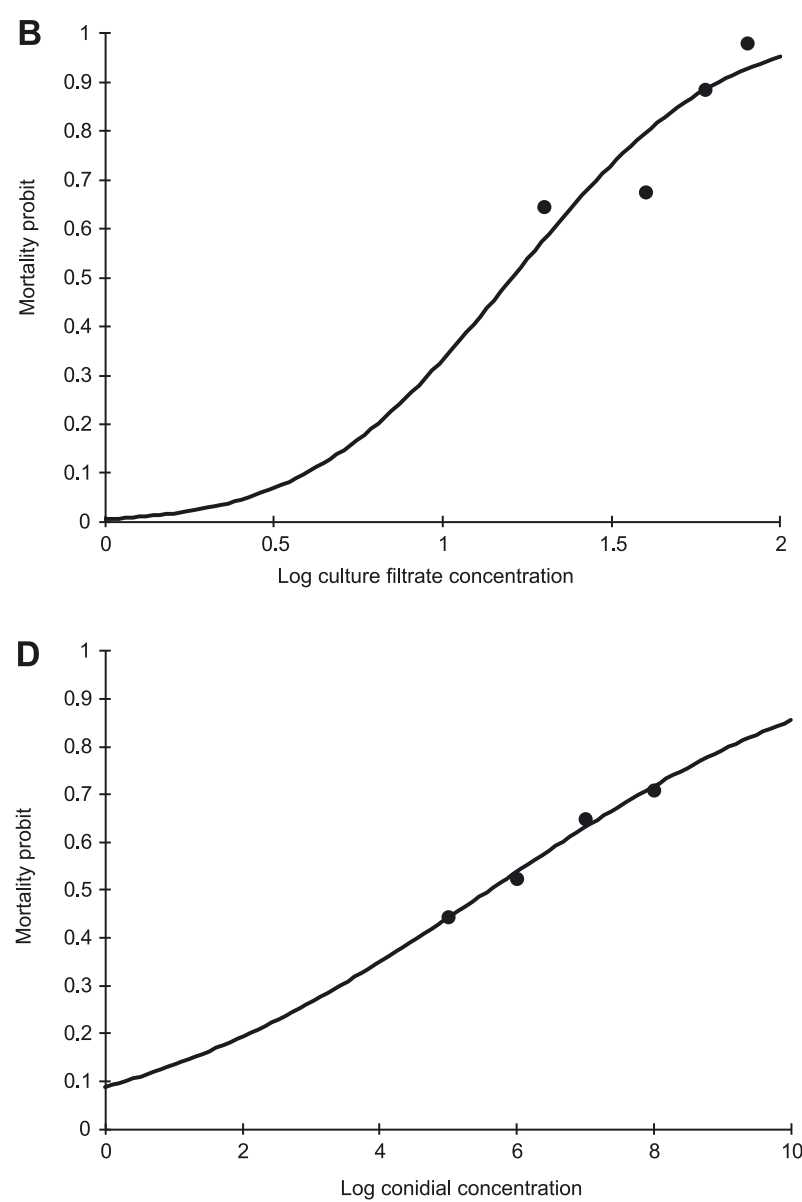

Fig. 2. Regression model of Aphis fabae mortality after probit-logit transformation, following treatments by Cladosporium oxysporum culture filtrates incorporated in aqueous suspension (A) and invert emulsion (B), conidial suspension incorporated in aqueous suspension (C) and invert emulsion (D) 


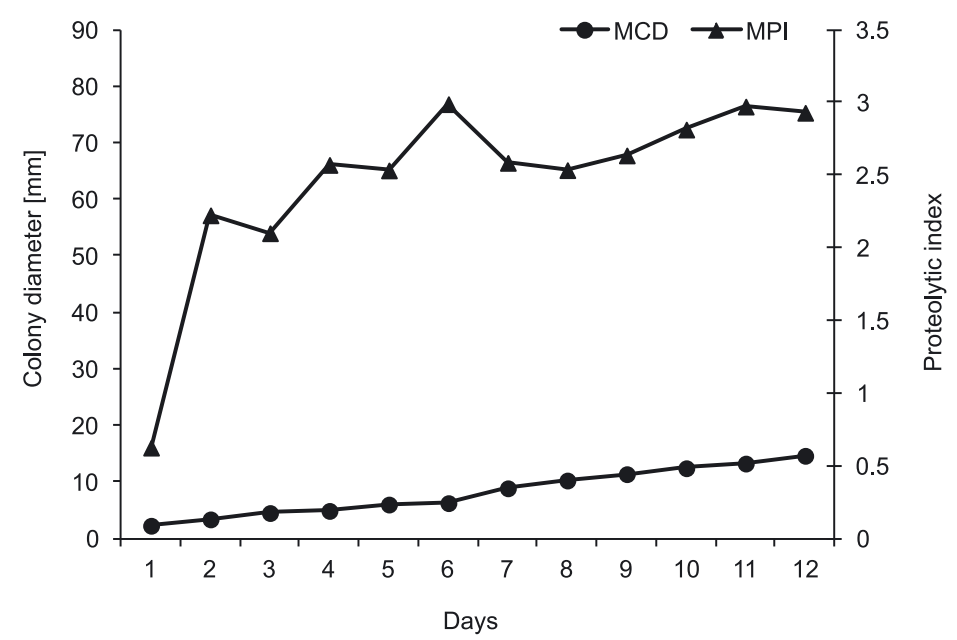

Fig. 3. Mean proteolytic index (MPI) vs. mean colony diameter (MCD) of Cladosporium oxysporum

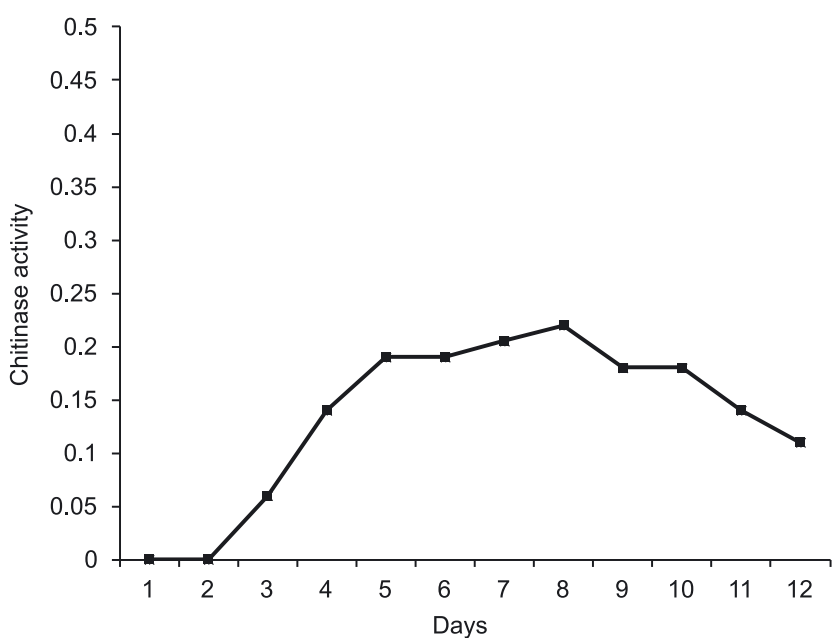

Fig. 4. Chitinase activity of Cladosporium oxysporum ( $\mu \mathrm{mol} \mathrm{N}$-acetyl- $\beta$-D-glucosamine $\min \cdot \mathrm{ml}^{-1}$ )

regarding the $\mathrm{LT}_{50}$ recorded for bioformulations containing fungal conidia. In fact, inverse emulsions were faster in action than aqueous suspensions, with an $\mathrm{LT}_{50}$ of $137.20 \mathrm{~h}$ and $167.04 \mathrm{~h}$ for the highest conidia concentration $\left(10^{8}\right.$. $\cdot \mathrm{ml}^{-1}$ ) incorporated into invert emulsions and aqueous suspensions, respectively (Table 2).

We evaluated the proteolytic activity of $C$. oxysporum for 12 days. Through the determination of the main proteolytic index (PI), we noticed that protease induction started from the first day (PI = 0.63) (Fig. 3) and increases quickly the 2 nd day $(\mathrm{IPM}=2.22)$. This gradual evolution of proteases continued until the 6th day, reaching a maximum of 2.99 , and then settling on the 7th day, always exceeding 2.50. Moreover, the radial growth of colonies was significantly slow because the average diameter reached $14.6 \mathrm{~mm}$, only on day 12 .

In addition, the chitinolytic activity of C. oxysporum culture filtrates showed a relatively weak width (Fig. 4). Initially, it was only from the 3rd day then it began to reach a maximum on the 8 th day $(0.22 \mu \mathrm{mol} \mathrm{N}$-acetyl- $\beta$-D-glucosamine $\left.\cdot \mathrm{h}^{-1}\right)$, only to decrease gradually until reaching $0.11 \mu \mathrm{mol} \cdot \mathrm{h}^{-1}$ the last day.

\section{Discussion}

Cladosporium is very diverse. Its diversity is illustrated not only at the specific "traditional" level, but also in terms of colonised biotopes. Detailed information on the bioecological components of this genus are mentioned in the reviews of McKemy and Morgan-Jones (1990); Ho et al. (1999); Heuchert et al. (2005) and Crous et al. (2007). Moreover, Cladosporium can include some naturally entomopathogenic members, experiencing biological control potentialities against several insect pests, particularly whiteflies (Aldeghairi et al. 2013). Among others, C. herbarum (Pers.) Link is active against species belonging to the genera: Aleurodicus, Bemisia, Aleurothrixus, and Dialeurodes (Rojas et al. 1998),

Cladosporium sp. isolated from aphids, against the coleopteran Tenebriodidae Alphitobius diaperinus (Panzer) (Rezende et al. 2009). Earlier, Petch (1931) showed that Cladosporium is able to attack aphids, and so C. oxysporum is associated with the Homoptera (Samways and Grech 1986). In addition, endophytic forms with entomopathogenic action have been isolated from the leaves of Coffea arabica L. (Vega et al. 2008) Schinus molle L. (Bensaci et al. 2012) and Nerium oleander L. (Bensaci et al. 2013). 
The treatments of $A$. fabae generated mortalities which differed according to: the bioformulation composition as well as the nature of the biological substrate. We noted that the invert emulsions showed more important aphicid action than that obtained by the aqueous suspensions. This remarkable efficiency was probably due to the particular make up of the invert emulsion's selected additives which improved the physical and chemical properties of the active biological fraction. The aqueous suspension, on the other hand, was simpler in term of added compounds.

In the beginning, the design of the biopesticides in invert emulsion formulation was obtained to control weeds and invasive plants in agricultural and aquatic ecosystems (Connick et al. 1991; Auld and McRae 1997), also to control plant pathogens (Batta 2003, 2004), and to a lesser degree, to control insect pests (Batta 2007). Its principle is based on the creation of a continuous oily phase within which is included a discontinuous aqueous phase. The purpose is to reduce the undesirable effects of the physical factors on the fungal filtrates, and to provide for the best conidial dispersion. In this way, the risks of volatilisation of the filtrates and loss of germination and the infectious capacity of conidia are limited.

Within the framework of the biological control of key crop pests, there have been few works which were devoted to the use of the culture filtrates of Cladosporium spp. By evaluating the effect of the culture filtrates of C. echinulatum (Berk.) G.A. de Vries and Paecilomyces sp. isolated from Nerium oleander L., against Acanthoscelides obtectus Say (Coleoptera, Bruchidae), Bensaci et al. (2013) obtained mortalities ranging from 39 to $84 \%$ for concentrations of 25 and $100 \%$, respectively. They also signaled that mortality is positively correlated to the culture filtrate concentration. In our study, the mortality of $A$. fabae was remarkable for inverse emulsions, indicating the compatibility of fungal filtrates with this type of preparation.

Furthermore, the use of conidial suspensions of Cladosporium is considered to be the most approved method by certain researchers, with regard to the proved entomo-infectious potentialities of this mycotaxon (Abdel-Baky and Abdel-Salam 2003; Saranya et al. 2010). Even if the mortalities obtained by the application of the formulations containing the conidial suspensions of the bioprospected fungus were much less than those obtained by use of the filtrates, it always proves that invert emulsions were more effective.

Saranya et al. (2010) showed that the conidial suspension of C. oxysporum generates a corrected mortality of $77.50 \%$ in Aphis craccivora Koch individuals, when the suspension was used at a concentration of $10^{8}$ conidia - $\mathrm{ml}^{-1}$ incorporated to the Teepol solution. This is contrary to our results where we noted that maximum mortality of A. fabae $(67.96 \%)$ is obtained with the same conidial concentration but incorporated in invert emulsion. It should be noted that the fungal origin is a spontaneous plant of the Aurès region (E. bupleuroides subsp. luteola) and so we did not make a study on the natural incidence of the isolated Cladosporium on the naturally-associated insects to the host plant. Moreover, Abdel-Baky and Abdel-Salam (2003) found that mortality generated naturally by three species of Cladosporium on A. craccivora, A. gossypii, and A. durantae varied from 16.41 to $28.08 \%$. It is impossible and premature to note that the tested endophyte of our study is "naturally entomopathogenic". Otherwise, it is acceptable to clarify the fact that it may adopt a "shift" strategy in its trophic behavior, which is the case for several endophytic fungi (Vega et al. 2008).

The values of the $\mathrm{LC}_{50}$ and earlier $\mathrm{LT}_{50}$ of invert emulsion demonstrate the effectiveness and speed of action compared to the aqueous suspensions. However, it seems that the fungus shows a very low infectious potential towards the aphids, and in fact, that is not truly desirable. The fungus probably acts by toxic bioactive metabolites rather than by the traditional way of mycoparasitic infection.

Saranya et al. (2010) calculated an $\mathrm{LC}_{50}$ of $7.4 \times 10^{5}$ conidia $\cdot \mathrm{ml}^{-1}$ and an $\mathrm{LT}_{50}$ of 5.24 days, corresponding to the application of the conidial suspension of $10^{8}$ conidia $\cdot \mathrm{ml}^{-1}$ derived from $C$. oxysporum against $A$. craccivora. In addition, Abdel-Baky and Abdel-Salam (2003) showed in a laboratory test, that maximum mortalities of A. gossypii (37.5\%) and $A$. craccivora ( $38 \%$ ) were recorded on the third day after treatment with conidial suspensions of Cladosporium spp. at a concentration of $10^{6}$ conidia $\cdot \mathrm{ml}^{-1}$. While Jeyarani et al. (2011) recorded an $\mathrm{LC}_{50}$ of $4.30 \times 10^{6}$ conidia $\cdot \mathrm{ml}^{-1}$ and an $\mathrm{LT}_{50}$ of $63.80 \mathrm{~h}$ after mite (Tetranychus urticae Koch) treatments with $C$. cladosporioides suspensions.

We noted that proteolytic potential of the tested C. oxysporum is relatively important. This enzymatic activity regarded as paramount for fungal endophytes, is reflected by the production or the induction of proteolytic enzymes such as the proteases and the polypeptidases (Kucera 1980; Samuels and Paterson 1995). Thus, it was demonstrated that enzymatic activities and the virulence of a broad range of fungi are two closely-dependant characters (Robert and Messing-Al-Aidroos 1985; Monod et al. 2002). The extent of the chitinolytic activity, though, cannot inform us about the aphicid potentialities of this endophyte. Yet, it is possible to attribute the infection of aphids treated with the conidial suspensions, to an affinity to the cuticle. Samways and Grech (1986) showed that C. oxysporum grown in media amended with chitin, is capable of inducing major diseases in Toxoptera citricidus and T. erytreae colonies.

We believe that the endophytic fungus $C$. oxysporum isolated from E. bupleuroides subsp. luteola shows aphicid potentials that can be exploited, with the choice of a suitable formulation, not only against $A$. fabae, but other crop-harmful aphid species. Thus, we note that invert emulsion is one of the appropriate formulations for the preparation and the design of the biological products containing mycoendophytes in their final state. Such a preparation and design are appropriate in the framework of biological and integrated control of aphids in semi-arid and arid agroecosystems.

\section{Acknowledgements}

We thank Prof. Malik Laamari for his technical contribution and for providing and identifying the tested aphids. 


\section{References}

Abbott W.S. 1925. A method of computing the effectiveness of an insecticide. Journal of Economic Entomology 18 (2): 265-267.

Abdel-Baky N.F., Abdel-Salam A.H. 2003. Natural incidence of Cladosporium spp. as a bio-control agent against whiteflies and aphids in Egypt. Journal of Applied Entomology 127 (4): 228-235.

Aldeghairi M.A., El-Meleigi M.A., Abdel Baky N.F., Ibrahim G.H. 2013. The entomopathogenic fungus Cladosporium sp. as a candidate biocontrol agent against the sweetpotato whitefly, Bemisia tabaci in Saudi Arabia. p. 532-563. In: “Recent Advances in Biofertilizers and Biofungicides (PGPR) for Sustainable Agriculture". Proceedings of 3rd Asian Conference on Plant Growth-Promoting Rhizobacteria (PGPR) and other Microbials. Manila, Philippines, 21-24 April 2013, 568 pp.

Assaf L.H. 2009. The efficiency of Beauveria bassiana (Bals.) Vuill. and Paecilomyces farinosus (Dicks ex Fr.) for biological control of bean aphid Aphis fabae Scopoli. p. 14-20. In: Proceedings of the 4th Conference on Recent Technologies in Agriculture. Cairo, Egypt, 3-5 November 2009.

Auld B.A., McRae C. 1997. Emerging technologies in plant protection - bioherbicides. p. 191-194. In: Proceedings of the 50th NZ Plant Protection Conference, New Zealand, 1997, 555 pp. http://www.nzpps.org/nzpp_contents.php?vol=50

Batta Y.A. 2003. Effect of treatment with Trichoderma harzianum Rifai formulated in invert emulsion on postharvest decay of apple blue mold. International Journal of Food Microbiology 96 (3): 281-288.

Batta Y.A. 2004. Postharvest biological control of apple grey mold by Trichoderma harzianum Rifai formulated in an invert emulsion. Crop Protection 23 (1): 19-26.

Batta Y.A. 2007. Biocontrol of almond bark beetle (Scolytus amygdali Geurin-Meneville, Coleoptera: Scolytidae) using Beauveria bassiana (Bals.) Vuill. (Deuteromycotina: Hyphomycetes). Journal of Applied Microbiology 103 (5): 1406-1414.

Bensaci O.A., Lombarkia N., Rouabah K. 2012. Endophytic fungi from Schinus molle L. as new biological control agents of black bean aphid in Algeria. p. 100. In: "IPM on the World Stage". 7th International Integrated Pest Management Symposium. Memphis, Tennessee, USA, 27-29 March 2012, 150 pp.

Bensaci O.A., Lombarkia N., Laib D.E. 2013. Initial evaluation of endophytic fungi, isolated from Nerium oleander L. for their biocontrol action against the bruchid Acanthoscelides obtectus (Say) (Coleoptera: Bruchidae) in Algeria. p. 162-167. In: "Endophytes for Plant Protection: the State of the Art". Proceedings of the 5th International Symposium on Plant Protection and Plant Health in Europe. Humboldt University Berlin, Berlin-Dahlem, Germany, 26-29 May 2013, 333 pp.

Bond D.A., Lowe H.J.B. 1975. Tests for resistance to Aphis fabae in field beans (Vicia faba). Annals of Applied Biology 81 (1): $21-32$.

Butt T.M., Goettel M.S. 2000. Bioassays of entomogenous fungi. p. 141-195. In: “Bioassays of Entomopathogenic Microbes and Nematodes" (A. Navon, K.R.S. Ascher, eds.). CAB International, Wallingford, UK, $324 \mathrm{pp}$.
Cammell M.E. 1981. The black bean aphid, Aphis fabae. Biologist 28: $247-258$.

Cammell M.E., Tatchell G.M., Woiwod I.P. 1989. Spatial pattern of abundance of the black bean aphid, Aphis fabae, in Britain. Journal of Applied Ecology 26 (2): 463-472.

Connick W.J., Daigle D.J., Quimby P.C. 1991. An improved invert emulsion with high water retention for mycoherbicide delivery. Weed Technology 5 (2): 442-444.

Crous P.W., Braun U., Schubert K., Groenewald J.Z. 2007. Delimiting Cladosporium from morphologically similar genera. Studies in Mycology 58 (1): 33-56.

Dedryver C.A. 1979. Déclenchement en serre d'une épizootie a Entomophthora fresenii sur Aphis fabae par introduction d'un inoculum et régulation de l'humidité relative. [Initiaiting an epizootic in a glasshouse with Enthomophtora fresenii on Aphis fabae through inoculum introduction and control of the relative humidity]. Entomophaga 24 (4): 443-453. (in French with English summary)

Dorschner K.W., Feng M., Baird C.R. 1991. Virulence of an aphidderived isolate of Beauveria bassiana (Fungi: Hyphomycetes) to the hop aphid, Phorodon humuli (Homoptera: Aphididae). Environmental Entomology 20 (2): 690-693.

Franz A., Katul L., Makkouk K.M., Vetten H.J. 1996. Monoclonal antibodies for the detection and differentiation of faba bean necrotic yellows virus isolates. Annals of Applied Biology 128 (2): 255-268.

Franz A.W., van der Wilk F., Verbeek M., Dullemans A.M., van den Heuvel J.F. 1999. Faba bean necrotic yellows virus (genus Nanovirus) requires a helper factor for its aphid transmission. Virology 262 (1): 210-219.

Giove R.M., Abis S. 2007. Place de la Méditerranée dans la production mondiale de fruits et légumes. [Place of the Mediterranean in the world production of fruits and vegetables]. Les notes d'analyse du CIHEAM 23: 1-21. (in French)

Guesmi-Jouini J., Boughalleb-Mhamdi N., Ben Halima-Kamel M. 2010. Etudes préliminaires sur les champignons entomopathogènes des pucerons de l'artichaut en Tunisie. [Preliminary studies on entomopathogenic fungi of artichoke aphids in Tunisia]. Entomologie Faunistique - Faunistic Entomology 63 (3): 171-181. (in French)

Halimona J., Jankevica L. 2011. The influence of entomophthorales isolates on aphids Aphis fabae and Metopeurum fuscoviride. Latvijas Entomologs 50: 55-60.

Hassan A.H.A. 2007. Novel natural products from endophytic fungi of Egyptian medicinal plants - chemical and biological characterization. Doctoral thesis, University of Düsseldorf, Germany, 270 pp.

Heuchert B., Braun U., Schubert K. 2005. Morphotaxonomic revision of fungicolous Cladosporium species (hyphomycetes). Schlechtendalia 13: 1-78.

Ho M.H.M., Castañeda R.F., Dugan F.M., Jong S.C. 1999. Cladosporium and Cladophialophora in culture: descriptions and an expanded key. Mycotaxon 72: 115-157.

Jeyarani S., Banu J.G., Ramaraju K. 2011. First record of natural occurrence of Cladosporium cladosporioides (Fresenius) de Vries and Beauveria bassiana (Bals.-Criv.) Vuill on two spotted spider mite, Tetranychus urticae Koch from India. Journal of Entomology 8 (3): 274-279.

Kucera M. 1980. Proteases from the fungus Metarhizium anisopliae toxic for Galleria mellonella larvae. Journal of Invertebrate Pathology 35 (3): 304-310. 
Kuk J.H., Jung W.J., Jo G.H., Kim Y.C., Kim K.Y., Park R.D. 2005. Production of N-acetyl-beta-D-glucosamine from chitin by Aeromonas sp. GJ-18 crude enzyme. Applied of Microbiological Biotechnology 68 (3): 384-389.

Lopez-Llorca L.V., Olivares-Bernabeu C.M., Salinas J., Jansson H.-B., Kolattukudy P.E. 2002. Pre-penetration events in fungal parasitism of nematode eggs. Mycological Research 106 (4): 499-506.

Maatougui M.E.H. 1996. Situation de la culture des fèves en Algérie et perspectives de relance. [The situation of bean crops in Algeria and the revival prospects]. Céréaliculture 29: 6-14. (in French)

McKemy J.M., Morgan-Jones G. 1990. Studies in the genus Cladosporium sensu lato. II. Concerning Heterosporium gracile, the causal organism of leaf spot disease of Iris species. Mycotaxon 39: 425-440.

Meradsi F. 2009. Contribution à l'étude de la résistance naturelle de la fève Vicia faba L. au puceron noir Aphis fabae Scopoli, 1763 (Homoptera: Aphididae). [Contribution to the study of natural resistance faba bean Vicia faba L. against the black aphid Aphis fabae Scopoli, 1763 (Homoptera: Aphididae)] Master degree thesis. University Hadj Lakhdar Batna, Algeria, 73 pp. (in French)

Mesquita A.L.M., Lacey L.A., Mercadier G., LeClant F. 1996. Entomopathogenic activity of a whitefly-derived isolate of Paecilomyces fumosoroseus (Deuteromycotina: Hyphomycetes) against the Russian wheat aphid, Diuraphis noxia (Hemiptera: Sternorrhyncha Aphididae) with the description of an effective bioassay method. European Journal of Entomology 93 (1): 69-75.

Monod M., Capoccia S., Lechenne B., Zaugg C., Holdom M., Jousson O. 2002. Secreted proteases from pathogenic fungi. International Journal of Medical Microbiology 292 (5-6): 405-419.

Moscoso I.L., Rosato Y.B. 1987. Extracellular enzyme production by haploids, heterocaryons and diploids of Aspergillus nidulans. Applied Microbiology and Biotechnology 26 (4): 365-368.

Nguyen V.N., Oh I.J., Kim Y.J., Kim K.Y., Kim Y.C., Park R.D. 2009. Purification and characterization of chitinases from Paecilomyces variotii DG-3 parasitizing on Meloidogyne incognita eggs. Journal of Industrial Microbiology and Biotechnology 36 (2): 195-203.

Petch T. 1931. Notes on entomogenous fungi. Transaction of the British Mycological Society 16 (1): 55-75.

Rezende S.R.F., Curvello F.A., Fraga M.E., Reis R.C.S., Castilho A.M.C., Agostinho T.S.P. 2009. Control of the Alphitobius diaperinus (Panzer) (Coleoptera: Tenebrionidae) with entomopathogenic fungi. Revista Brasileira de Ciencia Avicola 11 (2): 121-127.

Robert A., Messing-Al-Aidroos K. 1985. Acid production by Metarhizium anisopliae: Effect on virulence against mosquitoes and on detection of in vitro amylase, protease, and lipase activity. Journal of Invertebrate Pathology 45 (1): 9-15.

Rojas T., Pons N., Arnal E. 1998. Cladosporium herbarum on whiteflies (Homoptera: Aleyrodidae) in Venezuela. Boletin de Entomologia Venezuela, Serie Monografias 13: 57-65.

Sabuquillo P., De Cal A., Melgarejo P. 2010. Development of a dried Penicillium oxalicum conidial formulation for use as a biological agent against Fusarium wilt of tomato: Selection of optimal additives and storage conditions for maintaining conidial viability. Biological Control 54 (3): 221-229.

Samuels R.I., Paterson I.C. 1995. Cuticle degrading proteases from insect moulting fluid and culture filtrates of entomopathogenic fungi. Comparative Biochemistry Physiology B 110 (4): 661-669.

Samways M.J., Grech N.M. 1986. Assessment of the fungus Cladosporium oxysporum (Berk. and Curt.) as a potential biocontrol agent against certain Homoptera. Agriculture, Ecosystem and Environment 15 (4): 231-239.

Saranya S., Ushakumari R., Sosamna J., Babu M.P. 2010. Efficacy of different entomopathogenic fungi against cowpea aphid, Aphis craccivora (Koch). Journal of Biopesticides 3 (1): 138-142.

Shah P.A., Clark S.J., Pell J.K. 2004. Assessment of aphid host range and isolate variability in Pandora neoaphidis (Zygomycetes: Entomophthorales). Biological Control 29 (1): 90-99.

Vega F.E., Posada F., Aime M.C., Pava-Ripoll M., Infante F., Rehner S.A. 2008. Entomopathogenic fungal endophytes. Biological Control 46 (1): 72-82.

Vetten H.J. 2010. Nanoviruses. p. 226-233. In: “Desk Encyclopedia of Plant and Fungal Virology" (B.W.J. Mahy, M.H.V. van Regenmortel, eds.). Elsevier, UK, 613 pp.

Wilding N., Mardell S.K., Brobyn P.J. 1986. Introducing Erynia neoaphidis into a field population of Aphis fabae: form of the inoculum and effect of irrigation. Annals of Applied Biology 108 (2): 373-385.

Yeo H., Pell J.K., Alderson P.G., Clark S.J., Pye B.J. 2003. Laboratory evaluation of temperature effects on the germination and growth of entomopathogenic fungi and on their pathogenicity to two aphid species. Pest Management Science 59 (2): 156-165 